\title{
Evolutionary fate of rhizome-specific genes in a non-rhizomatous Sorghum genotype
}

\author{
CS Jang ${ }^{1,2}$, TL Kamps ${ }^{1,3}$, H Tang $^{1}$, JE Bowers ${ }^{1}$, C Lemke $^{1}$ and AH Paterson ${ }^{1}$ \\ ${ }^{1}$ Plant Genome Mapping Laboratory, University of Georgia, Athens, GA, USA and ${ }^{2}$ Plant Genomics Lab, Department of Applied Plant \\ Sciences Technology, Kangwon National University, Chuncheon, Korea
}

\begin{abstract}
What is the fate of organ-specific genes after the organ is lost? For Sorghum propinquum and Sorghum halepense genes that were previously shown to have rhizome-enriched expression, we have conducted comparative analysis of both coding regions and regulatory sequences in Sorghum bicolor (non-rhizomatousness) and $S$. propinquum (rhizomatousness). Most genes with rhizome-enriched expression appear to have similar numbers of paralogous copies in both genotypes, with only three of 24 genes studied showing significant differences in copy numbers. We detected no greater propensity for mutation in $S$. bicolor than in $S$. propinquum of genes with rhizome-enriched expression in the latter. Several cis-acting regulatory elements, particularly an Myb-binding core (AACGG) that is involved in the regulation of the mitotic cyclin, were more abundant in
\end{abstract}

Keywords: evolutionary fate; polyploidy; rhizome; sorghum

\section{Introduction}

Rhizomes, modified subterranean stems that are diageotropic (for example, orient their growth perpendicular to the force of gravity), are organs of fundamental importance to plant competitiveness and invasiveness, playing two contrasting roles in agriculture. As a primary means of dispersal, rhizomes are an important component of 'weediness' of many of our most noxious weeds, including Johnsongrass (Sorghum halepense L. Pers.), Bermuda grass (Cynodon dactylon L. Pers.), purple nutsedge (Cyperus rotundus), quack grass (Agropyron repens) and cogon grass (Imperata cylindrica).

By contrast, rhizomes are also a valuable asset in establishment and persistence of dense, productive stands of forage and turfgrasses cultivated on more than 60 million acres in the southern United States alone (Burton, 1989), including Cynodon spp. (bermudagrass), Paspalum spp. (bahia and dallisgrass), Pennisetum/Cenchrus spp. (buffelgrass) and many others. The expansion of agriculture to provide plant biomass for production of fuels or chemical feedstocks will require greater utilization of marginal lands to make production of low per-unit value biomass economical.

Correspondence: Professor AH Paterson, Plant Genome Mapping Laboratory, University of Georgia, Athens, GA 30602, USA.

E-mail: paterson@uga.edu

${ }^{3}$ Current address: Horticultural Sciences Department, University of Florida, Gainesville, FL 32611, USA.

Received 6 May 2008; revised 14 October 2008; accepted 19 October 2008; published online 12 November 2008 promoters of $S$. propinquum than in non-rhizomatous S. bicolor or Oryza sativa (rice). We suggest that many genes with rhizome-enriched expression in $S$. propinquum may serve multiple functions, with partial loss of some of these functions in $S$. bicolor but ongoing purifying selection acting to preserve the remaining functions. Expressed genes in polyploid $S$. halepense rhizomes appeared to be more frequently derived from the $S$. propinquum than the $S$. bicolor progenitor, but there was some evidence of formation of novel alleles and 'recruitment' of $S$. bicolor genes to rhizomeenriched expression in $S$. halepense, suggesting that polyploidy may have offered new evolutionary potential to S. halepense.

Heredity (2009) 102, 266-273; doi:10.1038/hdy.2008.119; published online 12 November 2008

The Sorghum genus has become a model for dissecting the molecular control of rhizomatousness (Paterson et al., 1995; Hu et al., 2003; Jang et al., 2006). S. halepense L. Pers. ( $2 N=2 X=40)$ (Johnsongrass) is one of the world's most noxious weeds (Holm et al., 1977), in part because it produces extensive rhizomes (subterranean stems that confer perenniality and also provide for clonal propagation) that make it difficult and expensive to eradicate. S. halepense is native to western Asia, but has been introduced and has naturalized in tropical and warm temperate climates worldwide (Holm et al., 1977). Cytological, morphological and molecular genetic data suggest that $S$. halepense is a naturally formed tetraploid hybrid derivative of Sorghum bicolor, an annual, polytypic African grass species which includes cultivated sorghum; and Sorghum propinquum, a perennial native to moist habitats in southeast Asia (Celarier, 1958; Doggett, 1976; Paterson et al., 1995).

Rhizomatousness appears to be ancestral within the Saccharinae clade. All members of the cultivated species, $S$. bicolor, are non-rhizomatous. However, close relatives are rhizomatous (S. propinquum), as is the ancestral form of a sister species, Saccharum spontaneum. These observations suggest that the loss of rhizomes in S. bicolor has been within the past $\sim 1$ million years since its divergence from a common ancestor shared with S. propinquum (Feltus et al., 2004). As all S. bicolor genotypes known, both wild and cultivated, are non-rhizomatous, the trait was presumably lost early in the radiation of S. bicolor.

What is the evolutionary fate of a gene that loses its organ? The evolutionary fate in non-rhizomatous 
genotypes of genes that formerly contributed to rhizome development is of interest both from a basic and a practical standpoint. From a basic standpoint, rhizomes are an excellent example of a case of 'organ loss' that can be genetically manipulated, perhaps shedding light on basic principles that may apply to understanding of the evolution of morphology of other organisms, for example, the fate of tail-specific genes in humans. From an applied standpoint, better understanding of the fates of rhizome-specific genes would shed some light on alternative models for how rhizomatousness was lost. For example, the elimination of rhizomes by the progressive shutdown of many genes may show a very different 'signature' in its impact on variation of gene sequences between rhizomatous and non-rhizomatous genotypes than an abrupt macro-mutation in one or a small number of genes. Several lines of evidence indicated that an abrupt macro-mutation in one or a small number of regulatory genes was responsible for other striking morphological modifications during crop domestication. For instance, selection in the regulatory region of the teosinte branched1 gene appears to have contributed substantially to the transformation of maize from the inflorescence morphology of the wild grass teosinte, with long branches with tassels (Wang et al., 1999; Clark et al., 2006), to the short branches typical of cultivated maize. Recently, Li et al. (2006) reported that reduced shattering of the mature inflorescence associated with rice domestication was caused in part by human selection of an amino acid substitution in the DNAbinding domain of the $s h 4$ gene. $R h z 2$ and $R h z 3$ might be targets for such macro-mutations affecting rhizomatousness (Hu et al., 2003). However, little is known on the fate of many genes involved in the molecular pathway after the genotype has lost the ability of rhizomatousness.

The nature of tetraploid $S$. halepense raises questions about the relative roles of diploid $S$. propinquum and $S$. bicolor alleles in the growth and development of Johnsongrass rhizomes. Johnsongrass ( $S$. halepense), with nearly worldwide distribution, is clearly more invasive than S. propinquum. Could this be partly due to recruitment of $S$. bicolor genes into rhizome development? To what degree has polyploid formation increased the potential for invasiveness of Johnsongrass?

Previously, we reported the functional classification, genomic organization, putative cis-acting regulatory elements, relationship to quantitative trait locus (QTL), of Sorghum genes with rhizome-enriched expression (Jang et al., 2006). However, the evolutionary fate in nonrhizomatous $S$. bicolor of genes with rhizome-enriched expression in its sister $S$. propinquum and possibly ancestral Saccharinae remains unknown. Herein, we have conducted comparative analysis of both coding regions and regulatory sequences for 54 rhizome tip (RT)-enriched genes isolated using bacterial artificial chromosome (BAC) libraries from S. bicolor and S. propinquum, seeking to shed new light on the evolution of rhizomatousness and the fates of genes whose organ is lost.

\section{Materials and methods}

Isolation of candidate BACs with rhizome-enriched genes Previously, genes with rhizome-enriched expression were identified from both genotypes, S. propinquum and
S. halepense, which produce abundant rhizomes (Jang et al., 2006). The 30 genes from S. propinquum and S. halepense, respectively, that showed the greatest enrichment of expression in the RT relative to mature rhizome internodes (RMIs) and pooled aboveground (AG) tissues were selected. Six clones that were enriched in $\mathrm{RT}$ relative to RMI were also RT-enriched relative to $\mathrm{AG}$, resulting in a total of 54 clones that were further analyzed herein. Overgo probes were designed from the sequences of each of 54 RT-enriched genes by BLAST comparison against other plant species to identify the most-conserved $40 \mathrm{bp}$ sequences as described (Bowers et al., 2005). For gene sequences with no matches to any other plant species, arbitrary $40 \mathrm{bp}$ sequences were used as overgo probes. Individual overgo probes were radioactively labeled (Yuksel and Paterson, 2005) and then hybridized to seven BAC filters including 40957 BACs of S. propinquum and 69545 BACs of S. bicolor as described (Bowers et al., 2005).

Candidate BACs of both genotypes possessing the respective alleles of rhizome-enriched genes were selected based on the hybridization data, also using an FPC database (http://www.plantgenome.uga.edu/). To confirm that positive BAC clones contained the correct locus and allele, gene-specific primer sets were designed using the Primer3 program (Rozen and Skaletsky, 2000) from cDNA sequences of each gene (data not shown) and then were used for PCR with BAC DNAs as templates. The $25 \mu \mathrm{l}$ PCR reaction mixtures contained $10 \mathrm{mM}$ Tri- $\mathrm{HCl} \mathrm{pH}$ $8.3,50 \mathrm{mM} \mathrm{KCl}, 1.5 \mathrm{mM} \mathrm{MgCl}_{2}, 0.1 \mathrm{mM}$ of each dNTP, $1.0 \mu \mathrm{M}$ of each of gene specific primers, $0.5 \mathrm{U}$ of Taq polymerase and $20 \mathrm{ng}$ of each template DNA. The PCR program was as follows: $5 \mathrm{~min}$ at $94^{\circ} \mathrm{C}, 35$ cycles $1 \mathrm{~min}$ at $94^{\circ} \mathrm{C}, 45-60 \mathrm{~s}$ at each annealing temperature and $1 \mathrm{~min}$ $72{ }^{\circ} \mathrm{C}$ with a 5 min final extension step at $72{ }^{\circ} \mathrm{C}$. The PCR products were directly sequenced using each genespecific primer after $15 \mathrm{~min}$ of incubation with $0.1 \mathrm{U}$ of shrimp alkaline phosphatase (Roche, Basel, Switzerland) and $0.1 \mathrm{U}$ of exonuclease I NEB; Ipswich, MA, USA) at $37^{\circ} \mathrm{C}$, followed by incubation at $80^{\circ} \mathrm{C}$.

\section{Shotgun libraries}

Each BAC clone was inoculated into a $3 \mathrm{ml}$ culture of Luria-Bertani (LB) medium with $12.5 \mu \mathrm{g} \mathrm{ml}^{-1}$ chloramphenicol, shaking at 250 r.p.m. for $4 \mathrm{~h}$ at $37^{\circ} \mathrm{C}$. A total of $50 \mu \mathrm{l}$ of culture were transferred into $50 \mathrm{ml}$ of the same antibiotic LB medium and then grown for 14-16 h. The cell pellets were suspended after adding $2 \mathrm{ml}$ of $10 \mathrm{mM}$ ethylenediaminetetraacetic acid (EDTA). The solutions were added $4 \mathrm{ml}$ of $0.2 \mathrm{~N} \mathrm{NaOH}, 1 \%$ SDS immediately followed by keeping tubes on ice after adding $3 \mathrm{ml}$ of $1.875 \mathrm{M}$ potassium acetate, $11.5 \%$ acetic acid. After centrifuging for $15 \mathrm{~min}$ at 12000 r.p.m., the solutions were filtered twice through Miracloth and $9 \mathrm{ml}$ of cold isopropanol added for DNA precipitation. The DNA pellets were dissolved in TE $(10 \mathrm{mM}$ Tris- $\mathrm{HCl} \mathrm{pH} 7.6$, $50 \mathrm{mM}$ EDTA), $1.15 \mathrm{ml}$ of $7.5 \mathrm{M}$ potassium acetate solution added, and frozen at $-80^{\circ} \mathrm{C}$ for $30 \mathrm{~min}$. After ethanol precipitation, DNA pellets were dissolved in $700 \mu \mathrm{l}$ of $50 \mathrm{mM}$ Tris- $\mathrm{HCl}, 50 \mathrm{mM}$ EDTA and then treated by $7 \mathrm{U}$ of RNase A (Sigma, St Louis, MO, USA) for $1 \mathrm{~h}$ at 50 r.p.m. at $37^{\circ} \mathrm{C}$. The solutions were extracted twice with phenol and precipitated with isopropanol/ethanol followed by re-suspending in $40 \mu \mathrm{l}$ of TE. BAC DNAs 
were sheared by using a Hydroshear (Gene Machines Inc., Ann Arbor, MI, USA) with parameters as follows; $200 \mu$ l DNA volume, 20 cycles and speed code 12 . The sheared DNAs were blunted-ended by using the End-It DNA End-Repair kit (Epicentre biotechnologies, Madison, WI, USA) in accordance with the manufacturer's instruction. The repaired DNAs were separated on a $1 \%$ agarose gel, sliced with size ranges of 3-4 kbp using a razor and extracted using a QIAEX II gel extraction kit (Qiagen, Valencia, CA, USA). The extracted DNAs were dephosphorylated by shrimp alkaline phosphatase (Roche) with incubation of $1 \mathrm{~h}$ at $37^{\circ} \mathrm{C}$. Ligation, transformation and blue/white screening were carried out using Zero Blunt TOPO PCR cloning kit (Invitrogen, Carlsbad, CA, USA) in accordance with the manufacturer's instruction.

\section{Picking, hybridization and sequencing}

A set of 768 clones derived from each BAC clone were picked using a QBOT (Genetix, New Milton, UK). Individual membranes containing 9216 clones with two replicates (that is, clones from six different BAC clones) were prepared as described by Jang et al. (2006). Probe labeling, hybridization and detection were conducted as described above. Twenty or fewer subclones per BAC clone were rearrayed into 96-well microtiter plates. Plasmid preparation and sequencing were performed by Jang et al. (2006). Trace files were processed using phred (score $>20)$, followed by phrap assembly into contigs by clustering a minimum continuous $100 \mathrm{bp}$ (Ewing and Green, 1998; Ewing et al., 1998). Assembled sequences were visualized and manually edited using Consed (Gordon et al., 1998).

\section{Sequence data analysis}

Gene structures of the assembled sequences were predicted by either of two methods. BLAST analysis was performed with the rhizome-enriched cDNA sequences against the nonredundant protein databases. Sequences of cDNAs and deduced amino acids were aligned to corresponding genomic sequences, thereby predicting gene structures using the NAP (Huang and Zhang, 1996) and the GAP2 (Huang, 1994) programs. Alternatively, gene structures were predicted by FGENESH gene prediction software (http://sun1.softberry. com/berry.phtml) with the training set for monocot plants. Orthologs of Oryza sativa corresponding to rhizome-enriched genes were retrieved from rice pseudomolecules (Version 4) using BLASTx analysis $\left(E<\mathrm{e}^{-25}\right)$. The deduced amino-acid sequences of $S$. propinquum, $S$. bicolor and $O$. sativa corresponding to each of rhizome-enriched genes were aligned with the ClustalW program (http://www.ebi.ac.uk/Tools/ clustalw/index.html) with default parameters, then manually edited using the BioEdit software (Hall, 1999). Synonymous and nonsynonymous substitutions per site $\left(K_{\mathrm{s}}\right.$ and $\left.K_{\mathrm{a}}\right)$ were measured by using the PAML package with the Nei-Gojobori method (Nei and Gojobori, 1986).

To uncover putative cis-acting regulatory elements located in the upstream regions of orthologs of rhizomeenriched genes, the identified $1-\mathrm{kb}$ sequences were analyzed by the signal scan search in the PLACE (http://www.dna.affrc.go.jp/PLACE, Higo et al., 1999) database. The confidence limits for a binomial proportion $(P=95 \%)$ were calculated according to standard methods (Snedecor and Cochran, 1980) and used to evaluate differences between orthologs in frequencies of ciselements.

\section{Results}

\section{BAC clones corresponding to RT-enriched genes from S. propinquum and S. bicolor}

By hybridization of gene-specific overgos, we have identified the BAC clones and number of contigs (genetic loci) at which family members of each gene are represented in the physical maps of both $S$. bicolor and S. propinquum (Bowers et al., 2005). A total of 24 genes of $S$. proqinquum were anchored to only one locus, whereas 17 genes occurred at 2-10 loci and 9 genes at more than 10 loci. Four genes were not anchored to any locus, although several nonoverlapping overgoes were used for screening. For S. bicolor, a total of 26 genes were anchored to only one locus, 17 to $2-10$ loci, 8 to more than 10 loci and 3 genes exhibited no anchor locus. The copy numbers for most RT-enriched genes were similar in S. bicolor and S. propinquum (Figure 1). One gene (RT/ RMI19) of unknown function showed remarkably higher abundance in S. bicolor (282 loci) than S. propinquum (one locus). In contrast, two genes, RT/RMI26 and RT/RMI27, showed substantially higher abundance (38 and 96 loci) in S. propinquum than S. bicolor (3 and 1 loci, respectively).

Because most genes appear to be present as multiple paralogs in a plant genome, it can be difficult to determine whether truly orthologous loci are being compared between genotypes (Newbury and Paterson, 2003). In order to identify truly orthologous loci of each RT-enriched gene from the two species studied, we chose candidate BAC clones based on the following three criteria: (1) identification of linkage groups which candidate BACs anchored to, in both genomes; (2) synteny of genetic markers between candidate BAC clones in both genomes and (3) chromosomal location of best-hit rice orthologs corresponding to each of the RTenriched genes. As shown in Supplementary Tables 1 and 2, a total of 20 out of 54 pairs were anchored to same

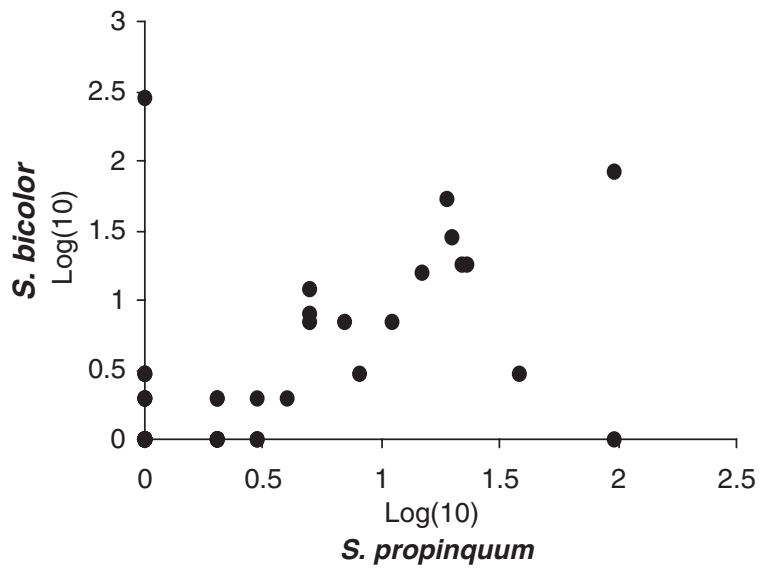

Figure 1 Comparison of putative copy numbers between genotypes, S. propinquum and S. bicolor. Copy numbers were estimated with the locus matched with more than two different BAC clones through FPC database when probing with single overgo. 
linkage groups in both genomes whereas 18 pairs were not anchored to any linkage group of either one of both genomes. Three pairs were anchored to different linkage groups.

\section{Genomic sequences corresponding to RT-enriched genes}

The candidate BACs were sheared by a hydroshear and the fragments ranging in size of from 2 to $3 \mathrm{kbp}$ were cloned. In order to get genomic sequences corresponding to RT-enriched genes, BACs were subcloned (see section 'Materials and methods') and the subclones screened for up to 20 matches with the overgoes used in screening of the candidate BAC clone. An average of 40 sequencing reactions (that is, two clones $\times 10$-fold sequencing reactions $\times$ both directions) per clone were conducted, making it possible to assemble about $5-6 \mathrm{kbp}$ of contiguous sequence, including most of each RTenriched gene. However, genes with long transcribed regions, for example RT/AG01 (and RT/RMI01) oligosaccharyl transferase STT3 protein with the transcribed region of $5237 \mathrm{bp}$ including 23 introns, required an additional cycle of hybridization with new overgoes designed near the $5^{\prime}$ proximity of the assembled region.

In RT-enriched genes obtained from RT/AG, fulllength coding region sequences of 11 allele pairs of both genotypes were assembled, with the remainder not obtained in either one or both genotypes (Supplementary Table 1). Putative promoter sequences of $1 \mathrm{kbp}$ or more of upstream sequence were obtained for eight gene pairs, whereas either one or both three genes pairs had less than $1 \mathrm{kbp}$ of upstream sequences.

A total of 16 full-length coding regions corresponding to RT-enrich genes from the comparison of RT/RMI were developed from both genotypes (Supplementary Table 2 ). One $\mathrm{kbp}$ or more of upstream sequences were obtained from both genotypes for 12 of these, whereas the other four included less than $1 \mathrm{kbp}$ upstream sequence from one or both.

\section{Genome origin of RT-enriched genes in S. halepense}

The genome organization of $S$. halepense, that is, a polyploid derived from interspecific hybridization of $S$. bicolor and S. propinquum, raises the question of whether there are striking differences in the abundance of transcripts from the respective diploids in $S$. halepense rhizomes. The respective diploid genomic DNAs corresponding to RT-enriched genes could allow us to determine the origins of transcripts in $S$. halepense rhizome. We used sequence-aligned scores produced by the ClustalW program (http://www.ebi.ac.uk/cgi-bin/ clustalw2) and/or BLAST 2 sequences (http:// www.ncbi.nlm.nih.gov/blast/bl2seq/wblast2.cgi) as a criterion to define the origin of the RT-enriched transcripts. Among the 24 gene pairs for which we obtained full-length transcribed regions from both genomic DNAs (Table 1), 12 were screened with overgoes of transcripts in S. halepense rhizomes. Six transcripts (50\%) in S. halepense rhizome were either identical (one cases) or significantly more similar (five, and the criteria for determining significance) to the genomic DNAs derived from $S$. propinquum than $S$. bicolor. One of the remaining six appeared to be a possible 'hybrid' transcript, more closely matching $S$. propinquum along the N-terminal part and S. bicolor along the C-terminal part although each of these matches was imperfect. The origin of the remainder could not be determined, either due to the identity of S. propinquum and S. bicolor DNAs (1 case), or to similar degrees of divergence from both. By contrast, most transcripts from $S$. propinquum rhizomes exhibited identity $(100 \%)$ to its genomic DNAs.

\section{Evolutionary fate of RT-enriched genes in S. bicolor}

The comparison of S. bicolor alleles of RT-enriched genes to those of $S$. propinquum might allow us to better understand the means by which rhizomatousness has been naturally shut off. Out of 24 RT-enriched genes for which their coding and upstream sequences were completely assembled, we detected no propensity for mutation in coding regions (for example, premature stop codon and striking amino-acid changes) in the nonrhizomatousness genotype as compared with those of the rhizomatousness genotype.

We then evaluated the mode of selection acting on RT-enriched genes in S. bicolor by the calculation of $K_{\mathrm{a}} / K_{\mathrm{s}}$ values as the divergence of $S$. bicolor and $S$. propinquum (Table 2). Contrary to our expectations, RT/AG-enriched transcripts showed $K_{\mathrm{a}} / K_{\mathrm{s}}$ values of $0.0000-0.3678$, suggesting purifying selection. Genetic distances between rice-sorghum orthologs corresponding to RTenriched genes was investigated to see if either branch (S. bicolor or S. propinquum) evolved faster. We detected no evidence of asymmetric evolution between $O$. sativaS. bicolor and O. sativa-S. propinquum (Table 2).

Similarly, for RT/RMI-enriched genes, a range of $K_{\mathrm{a}} /$ $K_{\mathrm{s}}$ values of $0.0000-0.5565$ suggested purifying selection after divergence of $S$. bicolor-S. propinquum. Again, $K_{\mathrm{a}} / K_{\mathrm{s}}$ values showed no significant differences between O. sativa-S. bicolor and O. sativa-S. propinquum, reflecting the symmetric evolution of $S$. bicolor and $S$. propinquum alleles. Three RT/RMI-enriched genes, all of unknown function, exhibited no correspondence to any rice gene.

\section{Orthologs corresponding to rhizome-enriched genes in other taxa}

BLAST $n$ analysis $\left(E<\mathrm{e}^{-25}\right)$ were performed with coding sequences of RT-enriched genes against expressed sequence tag (EST) databases of each of five major crops including Sorghum, Saccharum, Zea, Triticum, Hordeum and Oryza as well as Arabidopsis as an outgroup. Of 24 RT-enriched genes, expressed sequence tag (EST) frequencies of 21 genes showed no obviously biases over the five major crops, showing their orthologs in most of the taxa. However, there is rare or none of EST frequency in Arabidopsis with the exception of RT/RMI02 (0.021\%). Curiously, three genes, that is, RT/RMI23, RT/RMI24 and RT/RMI26, each of which exhibited no correspondence to the rice genome, evidenced highest frequencies abundance in Sorghum and were also found in closely related Saccharum and Zea but were absent from cDNA resources for the remaining, more distantly related taxa (Figure 2).

\section{Comparison of putative cis-acting regulatory element}

The discovery that changes in the promoter regions of genes related to domestication may be more important than changes in the coding regions (Wang et al., 1999) raised the question of whether changes in promoters of many genes related to rhizomatousness might be found. 
Table 1 Genome origins of transcripts in S. halepense rhizomes

\begin{tabular}{|c|c|c|c|c|c|c|}
\hline \multirow{2}{*}{ No. of genes ${ }^{\mathrm{a}}$} & \multirow{2}{*}{ No. of BAC clones $^{\mathrm{b}}$} & \multicolumn{2}{|c|}{${ }^{c D N A \text { origin }^{c}}$} & \multicolumn{3}{|c|}{ Similarity of S. halepense $c D N A^{\mathrm{d}}$} \\
\hline & & S. propinquum & S. halepense & S. propinquum & S. bicolor & $N D^{\mathrm{e}}$ \\
\hline 54 & 24 & 12 & 12 & 6 & 0 & 6 \\
\hline \multicolumn{7}{|c|}{ 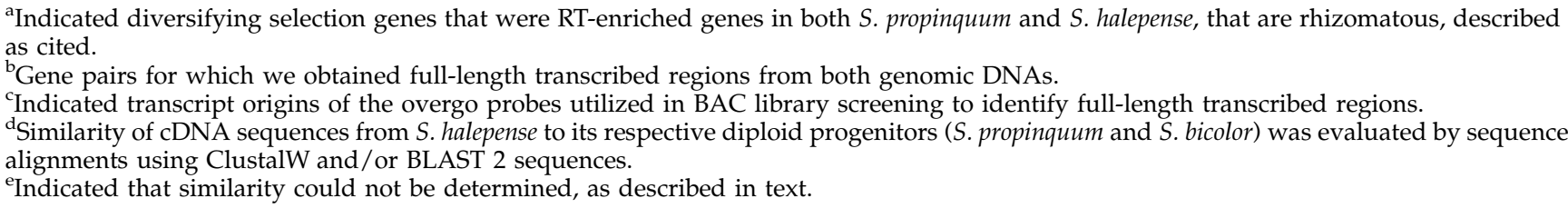 } \\
\hline
\end{tabular}

Table 2 Evaluation of $K_{\mathrm{a}} / K_{\mathrm{s}}$ value between S. propinquum genes with rhizome-enriched expression patterns and their orthologous genes of S. bicolor or O. sativa

\begin{tabular}{|c|c|c|c|c|c|c|c|c|c|}
\hline \multirow[t]{2}{*}{ Clone ID } & \multicolumn{3}{|c|}{ S. propinquum vs S. bicolor } & \multicolumn{3}{|c|}{ S. propinquum vs O. sativa } & \multicolumn{3}{|c|}{ S. bicolor vs O. sativa } \\
\hline & $K_{\mathrm{a}}$ & $K_{\mathrm{s}}$ & $K_{\mathrm{a}} / K_{\mathrm{s}}$ & $K_{\mathrm{a}}$ & $K_{\mathrm{s}}$ & $K_{\mathrm{a}} / K_{\mathrm{s}}$ & $K_{\mathrm{a}}$ & $K_{\mathrm{s}}$ & $K_{\mathrm{a}} / K_{\mathrm{s}}$ \\
\hline \multicolumn{10}{|c|}{ High RT/AG group } \\
\hline RT/AG01 & 0.0000 & 0.0105 & 0.0000 & 0.0241 & 0.4313 & 0.0559 & 0.0241 & 0.4309 & 0.0560 \\
\hline RT/AG02 & 0.0000 & 0.0707 & 0.0000 & 0.0113 & 0.3738 & 0.0301 & 0.0113 & 0.4120 & 0.0273 \\
\hline RT/AG05 & 0.0010 & 0.0144 & 0.0679 & 0.2675 & 0.7202 & 0.3713 & 0.2676 & 0.7115 & 0.3761 \\
\hline RT/AG06 & 0.0023 & 0.0068 & 0.3361 & 0.1501 & 0.4625 & 0.3245 & 0.1501 & 0.4680 & 0.3208 \\
\hline RT/AG07 & 0.0219 & 0.0595 & 0.3678 & 0.1859 & 0.4231 & 0.4393 & 0.1785 & 0.4132 & 0.4319 \\
\hline RT/AG10 & 0.0030 & 0.0203 & 0.1490 & 0.0750 & 0.4987 & 0.1503 & 0.0739 & 0.4820 & 0.1532 \\
\hline RT/AG11 & 0.0029 & 0.0203 & 0.1407 & 0.0846 & 0.6690 & 0.1264 & 0.0824 & 0.6554 & 0.1258 \\
\hline RT/AG16 & 0.0010 & 0.0266 & 0.0391 & 0.0516 & 0.5870 & 0.0880 & 0.0522 & 0.5628 & 0.0927 \\
\hline RT/AG19 & 0.0013 & 0.0240 & 0.0525 & 0.3319 & 0.6701 & 0.4952 & 0.3324 & 0.6686 & 0.4971 \\
\hline RT/AG20 & 0.0000 & 0.0000 & NA & 0.1021 & 0.3145 & 0.3247 & 0.1021 & 0.3145 & 0.3247 \\
\hline RT/AG22 & 0.0026 & 0.0161 & 0.1585 & 0.1469 & 0.3489 & 0.4209 & 0.1462 & 0.3516 & 0.4159 \\
\hline RT/AG25 & 0.0097 & 0.0423 & 0.2301 & 0.0744 & 1.0657 & 0.0699 & 0.0745 & 1.0789 & 0.0690 \\
\hline \multicolumn{10}{|c|}{ High RT/RMI group } \\
\hline RT/RMI01 & 0.0000 & 0.0105 & 0.0000 & 0.0241 & 0.4313 & 0.0559 & 0.0241 & 0.4309 & 0.0560 \\
\hline RT/RMI02 & 0.0000 & 0.0707 & 0.0000 & 0.0113 & 0.3738 & 0.0301 & 0.0113 & 0.4120 & 0.0273 \\
\hline RT/RMI03 & 0.0060 & 0.0114 & 0.5213 & 0.0721 & 0.7505 & 0.0961 & 0.0682 & 0.7310 & 0.0933 \\
\hline RT/RMI04 & 0.0023 & 0.0068 & 0.3361 & 0.1501 & 0.4625 & 0.3245 & 0.1501 & 0.4680 & 0.3208 \\
\hline RT/RMI06 & 0.0010 & 0.0266 & 0.0391 & 0.0516 & 0.5870 & 0.0880 & 0.0522 & 0.5628 & 0.0927 \\
\hline RT/RMI10 & 0.0024 & 0.0233 & 0.1073 & 0.1603 & 0.7085 & 0.2263 & 0.1612 & 0.6874 & 0.2345 \\
\hline RT/RMI11 & 0.0093 & 0.0349 & 0.2661 & 0.0989 & 0.7297 & 0.1355 & 0.0926 & 0.6903 & 0.1342 \\
\hline RT/RMI16 & 0.0030 & 0.0618 & 0.0493 & 0.2219 & 0.4475 & 0.4960 & 0.2188 & 0.4586 & 0.4771 \\
\hline RT/RMI18 & 0.0214 & 0.0546 & 0.2274 & 0.1873 & 0.6438 & 0.2909 & 0.1840 & 0.6315 & 0.2914 \\
\hline RT/RMI20 & 0.0000 & 0.0094 & 0.0000 & 0.2122 & 0.3329 & 0.6374 & 0.2122 & 0.3185 & 0.6661 \\
\hline RT/RMI23 & 0.0163 & 0.0294 & 0.5565 & - & - & ND & - & - & ND \\
\hline RT/RMI24 & 0.0063 & 0.0349 & 0.1813 & - & - & ND & - & - & ND \\
\hline RT/RMI26 & 0.0052 & 0.0188 & 0.3121 & - & - & ND & - & - & ND \\
\hline RT/RMI27 & 0.0000 & 0.0044 & 0.0000 & 0.0262 & 0.5112 & 0.0513 & 0.0262 & 0.5114 & 0.0513 \\
\hline RT/RMI28 & 0.0037 & 0.0148 & 0.2944 & 0.5030 & 0.5854 & 0.2971 & 0.2971 & 0.5091 & 0.5835 \\
\hline RT/RMI30 & 0.0017 & 0.0163 & 0.1037 & 0.2573 & 0.5220 & 0.4929 & 0.2598 & 0.5541 & 0.4689 \\
\hline
\end{tabular}

Abbreviations: AG, aboveground; NA, not applicable; ND, not determined; RMI, rhizome internode; RT, rhizome tip.

To evaluate putative cis-acting regulatory elements, upstream regions of $S$. bicolor and $S$. propinquum genes were analyzed using the PLACE database. The upstream regions of 21 rice orthologs of RT-enriched genes were also retrieved from rice pseudomolecules and used as another control set due to the non-rhizomatous nature of O. sativa. Comparison of these regions in this sample of rhizome-enriched genes permits us to infer changes in upstream features associated with the general class of rhizome-enriched genes since the divergence of $S$. bicolor from S. propinquum or since the divergence of either of these from rice.

One cis-acting regulatory element, an Myb-binding core (AACGG) which is involved in the regulation of the mitotic cyclin, especially as an activator element, found in the promoter of the Arabidopsis thaliana cyclin B1 gene (Planchais et al., 2002), was significantly more abundant in promoters of $S$. propinquum alleles $(70.8 \%)$ than those of S. bicolor $(54.2 \%)$ or O. sativa $(47.6 \%)$. Five additional cis-acting regulatory elements, such as CRT/DRE motif (Xue, 2003), (CA) $)_{n}$ element in storage protein genes (Ellerstrom et al., 1996), TATA box (Grace et al., 2004), the CCA1-binding element related to regulation by phytochrome (Wang et al., 1997), and pyrimidine box required for gibberellic acid (GA) induction (Cercos et al., 1999), were also more abundant in $S$. propinquum than either S. bicolor or O. sativa alleles (Table 3).

Several cis-acting regulatory elements were more abundant in promoters of S. bicolor than in S. propinquum or O. sativa (Table 3). One motif found in promoters of 
anaerobic genes (AAACAAA; Mohanty et al., 2005) showed significantly higher abundance in $S$. bicolor than the other species. The promoters of $S$. bicolor genes were enriched relative to those of $O$. sativa for three additional cis-elements, -300 element (Thomas and Flavell, 1990), -10 promoter element (Thum et al., 2001) and TATA box (Grace et al., 2004). By contrast, two promoters, polyA signal (O'Nell et al., 1990) and pro- or hypo-osmolarity element found in the promoter of proline dehydrogenase (Satoh et al., 2002) were more abundant in the promoters of $S$. bicolor than $S$. propinquum alleles.

\section{Discussion}

Although mutations of a tiny population of major regulatory gene(s) followed by human selection are well known to be responsible for crop morphological mod-

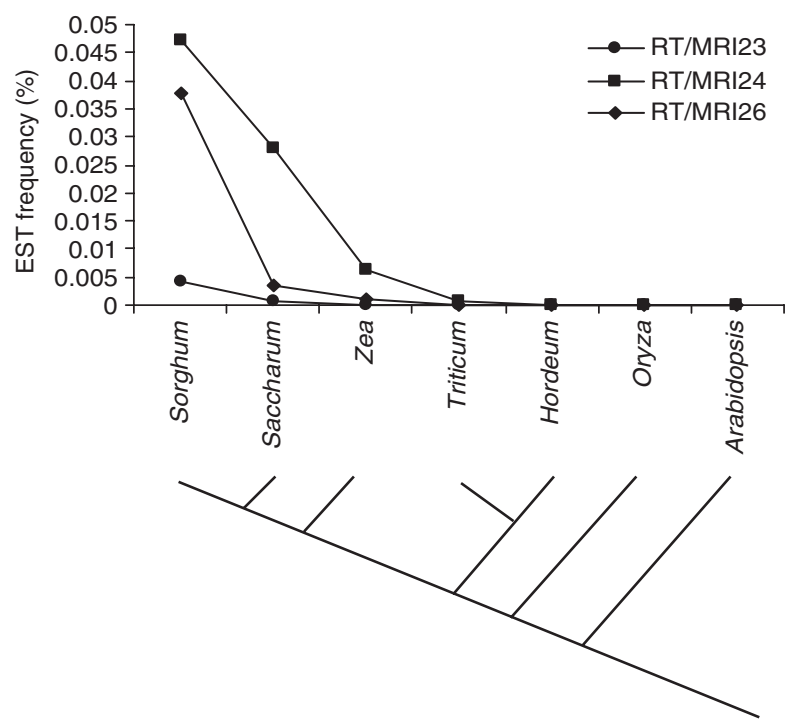

Figure 2 EST frequencies of homologs of three rhizome tip (RT)enriched genes (RT/RMI23, RT/RMI24 and RT/RMI26), in five major crop plants and Arabidopsis. ification during domestication, little is known about the evolutionary fate of additional genes which might be affected by such morphological modifications. We found that the loss of rhizomes in the lineage leading to $S$. bicolor has had very little effect on genes that show rhizome-enriched expression in S. propinquum. Indeed, these genes continue to show evidence of purifying selection since the $S$. bicolor-S. propinquum divergence, suggesting that the elimination of rhizomes has not been by the progressive shutdown of many genes.

Some hypotheses might be able to explain our finding that most rhizome-enriched genes have been not mutated in the genotype (for example, S. bicolor) that has lost the ability to make rhizomes. The small $K_{\mathrm{a}} / K_{\mathrm{s}}$ ratios observed for the 24 genes suggests that they remain under purifying selection. Indeed, not a single gene among the 24 showed $K_{\mathrm{a}} / K_{\mathrm{s}}>1$, which would be suggestive of diversifying selection; or even $K_{\mathrm{a}} / K_{\mathrm{s}} \sim 1$, suggestive of a lack of functional constraint (pseudogenization). An attractive hypothesis is that the RT-enriched genes may serve multiple functions during growth and development of plants, some of which are not in rhizomes. Regulatory, rather than structural, mutations might have been responsible for the loss of rhizomatousness in S. bicolor, as suggested by significant differences of one type of cis-element between $S$. propinquum and $S$. bicolor as well as O. sativa. Planchais et al. (2002) reported that one promoter region including the Myb-binding core (AACGG) took part in the cell-cycle-dependent transcriptional regulation of the $A$. thaliana cyclin B1 gene. The $C y c B 1$ gene is localized to lateral root primodia, the base of the first leaf promodium and the shoot meristem, suggesting that its accumulation might be one of the limiting factors for the activation of cell division (Ferreira et al., 1994). Significant differences in abundance of the Myb core sequence between the promoters of S. propinquum and S. bicolor (or O. sativa) might reflect loss of one or more subfunctions of RT-enriched alleles in S. bicolor due to loss of regulatory motifs important to rhizome-specificity. The core of the $(\mathrm{CA})_{n}$ element, required for storage organ-specific

Table 3 Summary of selected cis-acting regulatory elements located on putative promoter sequences of genes with rhizome-enriched expression patterns and their rice orthologs

\begin{tabular}{|c|c|c|c|c|}
\hline & & S. propinquum & S. bicolor & O. sativa \\
\hline No. of tested clones & & 24 & 24 & 21 \\
\hline Total promoter length $(\mathrm{bp})$ & & 20749 & 20749 & 17749 \\
\hline \multicolumn{5}{|c|}{ Cis-elements enriched in S. propinquum } \\
\hline Myb core & AACGG & $70.8 \pm 18.2^{\mathrm{a}}$ & $54.2 \pm 19.9$ & $47.6 \pm 16.7$ \\
\hline CRT/DRE motif & GTCGAC & $33.3 \pm 18.9$ & $16.7 \pm 14.9$ & $19.3 \pm 16.7$ \\
\hline$(\mathrm{CA})_{n}$ element & CNAACAC & $45.8 \pm 19.9$ & $29.2 \pm 18.1$ & $21.2 \pm 16.7$ \\
\hline TATA box & TATATAA & $58.3 \pm 19.7$ & $45.8 \pm 19.9$ & $14.3 \pm 15.0$ \\
\hline CCA1 binding & AAMAATCT & $16.7 \pm 14.9$ & $4.2 \pm 8.0$ & $9.5 \pm 12.6$ \\
\hline Pyrimidine box & TTTTTTCC & $16.7 \pm 14.9$ & $4.2 \pm 8.0$ & $2.9 \pm 19.3$ \\
\hline \multicolumn{5}{|c|}{ Cis-elements enriched in S. bicolor } \\
\hline-300 ELEMENT & TGHAAARK & $50.0 \pm 20.0$ & $62.5 \pm 19.4$ & $38.1 \pm 20.1$ \\
\hline-10 promoter element & TATTCT & $33.3 \pm 18.9$ & $45.8 \pm 19.9$ & $23.8 \pm 18.2$ \\
\hline TATA box & TATAAAT & $37.5 \pm 19.4$ & $54.2 \pm 19.9$ & $33.3 \pm 20.2$ \\
\hline PolyA signal & AATTAAA & $12.5 \pm 13.2$ & $29.2 \pm 18.2$ & $23.8 \pm 18.2$ \\
\hline PRE & ACTCAT & $20.8 \pm 16.2$ & $41.7 \pm 19.7$ & $28.5 \pm 19.3$ \\
\hline Anaerobic set & AAACAAA & $45.8 \pm 19.9$ & $70.8 \pm 18.2$ & $42.9 \pm 21.2$ \\
\hline
\end{tabular}

a Percentage of the indicated element family found per putative promoter region $\pm 95 \%$ confidence limits for $P$. 
transcription (Ellerstrom et al., 1996), also showed lower frequencies in the promoter regions of $S$. bicolor and O. sativa than S. propinquum.

Another possibility for partial loss of subfunctions of the RT-enriched genes in domesticated genotypes would be that an alternative splice form with rhizomespecificity is lost but the other form(s) still remain due to their importance in other organs. For example, a gene-encoding oligosaccharyl transferase STT3 protein with the highest degree of rhizome-specific expression (both RT/AG and RT/RMI) and located near a QTL which contributes to rhizome length and number, rhizome branching, and RMI number and length (Jang et al., 2006) evidenced the longest transcribed region with as many as 23 introns. In its rice ortholog (Os05g44360), two different splice isoforms have been reported (http://www.tigr.org/tigr-scripts/euk_manatee/shared/ ORF_infopage.cgi).

Another alternative hypothesis is that rhizome-enriched overexpression of these genes is a 'mistake', that is, that offers no particular fitness advantages to the plant, much like expression of some retroelements (for example, Langille and Clark, 2007), but that their expression at low levels somewhere else in the plant is important.

The aggressive rhizomatousness and widespread international distribution of tetraploid $S$. halepense raised interesting questions-that is, whether alleles from nonrhizomatous $S$. bicolor may have played any role in the aggressive rhizomatousness of $S$. halepense. It is believed that polyploidization can lead to extensive effects on gene expression, as detailed above. Although there is greater abundance of transcripts from $S$. propinquum (50\%) than S. bicolor in S. halepense rhizomes, we do not yet have sufficient information to define the remainders of transcripts of $S$. halepense rhizomes (50\%). It remains to be determined, for example, whether different alleles from the respective diploids might have interacted to form a new allele, which could lead to regaining of function even if the $S$. bicolor portion had been nonfunctionalized (Wang et al., 2007).

Most RT-enriched genes (51 of 54 genes tested) showed no significant differences in gene copy numbers between S. propinquum and S. bicolor, with a few exceptions. Three RT-enriched genes did show significant differences in numbers of gene copies, suggesting gene amplification following speciation. Naito et al. (2006) reported dramatic amplification of a rice-transposable element designed as mPing during domestication, suggesting that the rapid increase represents a potentially valuable source of population diversity. Although the nature of the three genes that are rapidly evolving in copy number is not yet clear, ongoing analysis of the 289 family members of RT/RMI19 in the recently completed genome sequence of $S$. bicolor might provide clues to shed further light on genome evolution following speciation.

The findings that three genes are relatively abundant in the sorghum EST database, and also present in other members of the Andropogoneae tribe but not in those of more distant plant taxa (Figure 2) might reflect more gradual amplification of these genes across many millions of years.

Previously, several lines of evidence pointed to GAs as probable key regulators of rhizome gene expression and development (Jang et al., 2006). In particular, three cis- acting elements related to GA responses were enriched in abundance in the putative promoter regions of rice gene models corresponding to sorghum genes with rhizomeenriched expression. One of these cis-elements (TTTTTTCC), the pyrimidine box for GA induction (Cercos et al., 1999), also showed higher frequency in the promoter regions of $S$. proqinquum alleles than those of $S$. bicolor or $O$. sativa, suggesting that they could contribute to the difference between these genotypes in the degree of rhizomatousness. Three cis-elements found in the previous report exhibited no significant differences in frequencies between the promoter regions of $S$. bicolor and $S$. propinquum and therefore are not likely to contribute to genetic differences between the two, but may still function in rhizome development and/or is important in GA regulation of other plant parts after loss of rhizomes in S. bicolor.

\section{Acknowledgements}

This work was supported in part by the USDA 'Biology of Weedy and Invasive Species' program (01-35320-10964 to AHP) and NSF Plant Genome Research Program (DBI9872649; 0115903 to AHP) and the Korean government (MOEHRD, Basic Research Promotion fund; Korea Research Foundation grant no. KRF-2004-214-M01-2004000-10060-0 to CSJ).

\section{References}

Bowers JE, Arias MA, Asher R, Avise JA, Ball RT, Brewer GA et al. (2005). Comparative physical mapping links conservation of microsynteny to chromosome structure and recombination in grasses. Proc Natl Acad Sci USA 102: 13206-13211.

Burton GW (1989). Progress and benefits to humanity from breeding warm-season forage grasses. In: Sleper DA, Asay $\mathrm{KH}$, Pedersen JF (eds). Contributions from Breeding Forages and Turf Grasses. Crop Science Society of America: Madison, WI. pp 21-29.

Celarier RP (1958). Cytotaxonomic notes on the subsection halepensia of the genus Sorghum Bull Torrey Bot. Club 85: 49-62.

Cercos M, Gomez-Cadenas A, Ho THD (1999). Hormonal regulation of a cysteine proteinase gene, EPB-1, in barley aleurone layers: cis- and trans-acting elements involved in the co-ordinated gene expression regulated by gibberellins and abscisic acid. Plant J 19: 107-118.

Clark RM, Wagler TN, Quijada P, Doebley J (2006). A distant upstream enhancer at the maize domestication gene $t b 1$ has pleiotropic effects on plant and inflorescent architecture. Nat Genet 38: 594-597.

Doggett H (1976). Sorghum. In: Simmonds NW (ed). Evolution of Crop Plants. Longman: Essex, UK. pp 112-117.

Ellerstrom M, Stalberg K, Ezcurra I, Rask L (1996). Functional dissection of a napin gene promoter: identification of promoter elements required for embryo and endospermspecific transcription. Plant Mol Biol 32: 1019-1027.

Ewing B, Green P (1998). Base-calling of automated sequencer traces using phred II error probability. Genome Res 8: 175-185.

Ewing B, Hiller L, Wendl MC, Green P (1998). Base-calling of automated sequencer traces using phred I accuracy assessment. Genome Res 8: 175-185.

Feltus FA, Wan J, Schulze SR, Estill JC, Jiang N, Paterson AH (2004). An SNP resource for rice genetics and breeding based on subspecies Indica and Japonica genome alignments. Genome Res 14: 1812-1819. 
Ferreira PCG, Hemerly AS, de Almedia Engler J, Van Montagu M, Engler G, Inzé D (1994). Developmental expression of the Arabiodpsis cycline gene cyc1At. Plant Cell 6: 1763-1774.

Gordon D, Abajian C, Green P (1998). Consed: a graphical toll for sequence finishing. Genome Res 8: 195-202.

Grace ML, Chandrasekharan MB, Hall TC, Crowe AJ (2004). Sequence and spacing of TATA box elements are critical for accurate initiation from the beta-phaseolin promoter. J Biol Chem 279: 8102-8110.

Hall TA (1999). BioEdit: a user-friendly biological sequence alignment editor and analysis program for window 95/ 98NT. Nucl Acids Symp Ser 41: 95-98.

Higo K, Ugawa Y, Iwamoto M, Korenaga T (1999). Plant cisacting regulatory DNA elements (PLACE) database: 1999. Nucleic Acids Res 27: 297-300.

Holm LG, Plucknett DL, Pancho JV, Herberger JP (eds) (1977). Sorghum halepense (L.) Pers. In: The World's Worst Weeds: Distribution and Biology. University Press of Hawaii: Honolulu, Hawaii. pp 54-61.

Hu FY, Tao DY, Sacks E, Fu BF, Xu P, Li J et al. (2003). Convergent evolution of perennially in rice and sorghum. Proc Natl Acad Sci USA 100: 4050-4054.

Huang X (1994). On global sequence alignment. Comput Appl Biosci 10: 227-235.

Huang X, Zhang J (1996). Methods for comparing a DNA sequence with a protein sequence. Comput Appl Biosci 12: 497-506.

Jang CS, Kamps TL, Skinner DN, Schulze SR, Vencill WK, Paterson AH (2006). Functional classification, genomic organization putatively cis-acting regulatory elements, and relationship to quantitative trait loci, of Sorghum genes with rhizome-enriched expression. Plant Physiol 142: 1148-1159.

Langille MGI, Clark DV (2007). Parent genes of retrotransposition-generated duplicates in Drosophila melanogaster have distinct expression profiles. Genomics 90: 334-343.

Li C, Zhou A, Sang T (2006). Rice domestication by reducing shattering. Science 311: 1936-1939.

Mohanty B, Krishnan SP, Swarup S, Bajic VB (2005). Detection and preliminary analysis of motifs in promoters of anaerobically induced genes of different plant species. Ann Bot 96: 669-681.

Naito K, Cho E, Yang G, Campbell MA, Yano K, Okumoto Y et al. (2006). Dramatic amplification of a rice transposable element during recent domestication. Proc Natl Acad Sci USA 103: 17520-17625.

Nei M, Gojobori T (1986). Simple methods for estimating the numbers of synonymous and nonsynonymous nucleotide substitutions. Mol Biol Evol 3: 418-426.

Newbury HJ, Paterson AH (2003). Genomic colinearity and its application in crop plant improvement. In: Newbury HJ (ed).
Plant Molecular Breeding. Blackwell Publishing: Oxford, UK. pp 60-82.

O'Nell SD, Kumagai MH, Majumdar A, Huand N, Sutliff TD, Rodriguez RL (1990). The alpha-amylase genes in Oryza sativa: characterization of cDNA clones and mRNA expression during seed germination. Mol Gen Genet 221: 235-244.

Paterson AH, Schertz KF, Lin Y-R, Liu S-C, Chang Y-L (1995). The weediness of wild plants: molecular analysis of genes influencing dispersal and persistence of johnsongrass, Sorghum halepense (L.) Pers. Proc Natl Acad Sci USA 92: 6127-6131.

Planchais S, Perennes C, Glab N, Mironov V, Inzé D, Bergouniox $C$ (2002). Characterization of cis-acting element involved in cell cycle phase-independent activation of Arath;CycB1;1 transcription and identification of putative regulatory proteins. Plant Mol Biol 50: 109-127.

Rozen S, Skaletsky HJ (2000). Primer3 on the WWW for general users and for biologist programmers. In: Krawetz $S$, Misener S (eds). Bioinformatics Methods and Protocols: Methods in Molecular Biology. Humana Press: Totowa, NJ. pp 365-386.

Satoh R, Nakashima K, Seki M, Shinozaki K, YanaguchiShinozaki K (2002). ACTCAT, a novel cis-acting element for proline- and hypoosmolarity-responsive expression of the ProDH gene encoding proline dehydrogenase in Arabidopsis. Plant Physiol 130: 709-719.

Snedecor GW, Cochran WG (1980). Statistical Methods. Iowa State University Press: Ames, IA. pp 110-121.

Thomas MS, Flavell RB (1990). Identification of an enhancer element for the endosperm-specific expression of high molecular weight glutenin. Plant Cell 2: 1171-1180.

Thum KE, Kim M, Morishiger DT, Eibl C, Koop HU, Mullet JE (2001). Analysis of barely chloroplast psbD light-responsive promoter elements in transplastomic tobacco. Plant Mol Biol 47: 353-366.

Wang R-L, Stec A, Hey J, Livak L, Doebley J (1999). The limits of selection during maize domestication. Nature 398: 236-239.

Wang X, Tang H, Bowers JE, Feltus FA, Paterson AH (2007). Extensive concerted evolution of rice paralogs and the road to regaining independence. Genetics 177: 1753-1763.

Wang Z-Y, Kenigsbuch D, Sun L, Harel E, Ong MS, Tobin EM (1997). A myb-related to transcription factor is involved in the phytochrome regulation of an Arabidopsis Lhcb gene. Plant Cell 9: 491-507.

Xue GP (2003). The DNA-binding activity of an AP2 transcriptional activator HvCBF2 involved in regulation of lowtemperature responsive genes in barley is modulated by temperature. Plant J 33: 373-383.

Yuksel B, Paterson AH (2005). Construction and characterization of a peanut HindIII BAC library. Theor Appl Genet 111 630-639.

Supplementary Information accompanies the paper on Heredity website (http://www.nature.com/hdy) 